\title{
Merging Single-Atom-Dispersed Silver and Carbon Nitride to a Joint Electronic System via Copolymerization with Silver Tricyanomethanide
}

Zupeng Chen, ${ }^{\dagger}$ Sergey Pronkin, ${ }^{\ddagger}$ Tim-Patrick Fellinger, $^{\dagger}$ Kamalakannan Kailasam, ${ }^{\S}$, Il Gianvito Vilé, ${ }^{\perp}$ Davide Albani, ${ }^{\perp}$ Frank Krumeich," Rowan Leary," Jon Barnard," John Meurig Thomas," Javier Pérez-Ramírez, ${ }^{\perp}$ Markus Antonietti, ${ }^{\dagger}$ and Dariya Dontsova* ${ }^{\dagger}$

${ }^{\dagger}$ Department of Colloid Chemistry, Max-Planck Institute of Colloids and Interfaces, Research Campus Golm, 14424 Potsdam, Germany

${ }^{\ddagger}$ Institut de Chimie et des Procédés pour l'Energie, l’Environnement et la Santé (ICPEES), ECPM, CNRS-Université de Strasbourg (UdS) UMR 7515, 25, rue Becquerel, 67087 Strasbourg, France

${ }^{\S}$ Institut für Chemie, Sekr. TC 2, Technische Universität Berlin, Englische Str. 20, 10587 Berlin, Germany

${ }^{\perp}$ Institute for Chemical and Bioengineering, Department of Chemistry and Applied Biosciences, and "Laboratory of Inorganic Chemistry, ETH Zürich, Vladimir-Prelog-Weg 1, 8093 Zürich, Switzerland

\# Department of Materials Science and Metallurgy, University of Cambridge, 27 Charles Babbage Road, Cambridge CB3 0FS, United Kingdom

\section{Supporting Information}

ABSTRACT: Herein, we present an approach to create a hybrid between single-atom-dispersed silver and a carbon nitride polymer. Silver tricyanomethanide (AgTCM) is used as a reactive comonomer during templated carbon nitride synthesis to introduce both negative charges and silver atoms/ions to the system. The successful introduction of the extra electron density under the formation of a delocalized joint electronic system is proven by photoluminescence measurements, X-ray photoelectron spectroscopy investigations, and measurements of surface $\zeta$ -

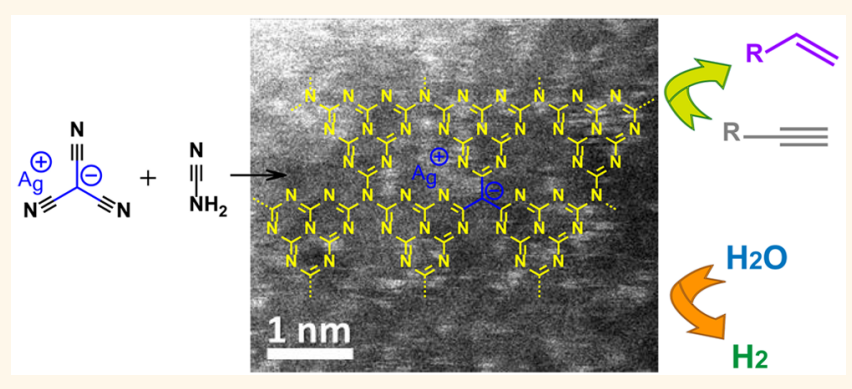
potential. At the same time, the principal structure of the carbon nitride network is not disturbed, as shown by solid-state nuclear magnetic resonance spectroscopy and electrochemical impedance spectroscopy analysis. The synthesis also results in an improvement of the visible light absorption and the development of higher surface area in the final products. The atom-dispersed AgTCM-doped carbon nitride shows an enhanced performance in the selective hydrogenation of alkynes in comparison with the performance of other conventional Ag-based materials prepared by spray deposition and impregnation-reduction methods, here exemplified with 1-hexyne.

KEYWORDS: carbon nitride, atomic dispersion, metal doping, copolymerization, joint electronic system, hydrogen evolution, selective hydrogenation

\footnotetext{
C arbon nitrides $(\mathrm{CN})$ with a stoichiometry close to $\mathrm{C}_{3} \mathrm{~N}_{4}$ are metal-free organic polymeric semiconductors that have recently attracted remarkable attention as visible light operating photocatalysts for water splitting, ${ }^{1-3}$ heterogeneous catalysts for various reactions (e.g., FriedelCrafts-type reactions, cyclization of functional nitriles ${ }^{4}$ ), catalyst supports, etc. Introduction of different metals into the carbon nitride network was performed in order to improve the lightharvesting ability of the polymer, by analogy with the working
}

principle of metal porphyrins and phthalocyanines. ${ }^{5}$ Another goal of metal doping is the preparation of highly active composite systems for various (photo)catalytic applications. Silver was previously introduced in $\mathrm{CN}$ polymer composites in

Received: July 8, 2015

Accepted: February 10, 2016

Published: February 10, 2016 
Scheme 1. Expected Modification of the Idealized Carbon Nitride Network Using Silver Tricyanomethanide

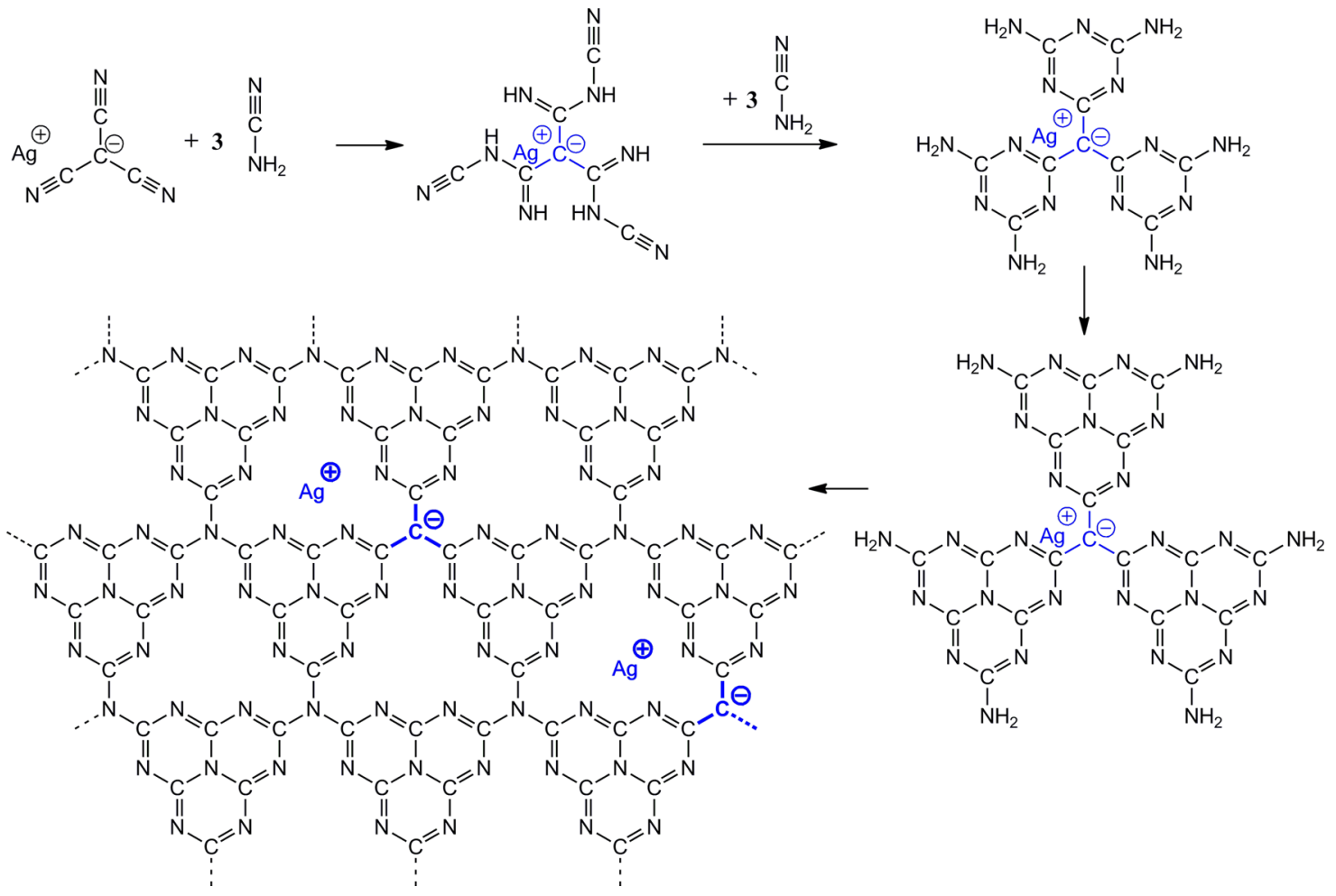

the form of nanoparticles (NPs) ${ }^{6-12}$ and as silver compounds being a second semiconductor (e.g., $\mathrm{Ag}_{3} \mathrm{PO}_{4},{ }^{13-16} \mathrm{Ag}_{2} \mathrm{O},{ }^{17}$ $\left.\mathrm{Ag}_{2} \mathrm{~S}^{18}{ }^{18} \mathrm{AgCl},{ }^{19} \mathrm{AgBr}^{20,21}\right)$, and improvements in the performance in photo- or photoelectrocatalytic reactions were reported. Typically, deposition of a metal at carbon nitrides is performed postsynthetically, by impregnation of prepared $\mathrm{CN}$ polymers with a metal salt, followed by metal reduction and/or heat treatment. This also leads to an undesirable decrease of the total surface area of the final composite compared to original material. Some examples related to the preparation of $\mathrm{Ag}$ containing $\mathrm{CN}$ composites illustrating this effect are deposition of $\mathrm{Ag}_{2} \mathrm{O}$ on mesoporous graphitic carbon nitride, mpg-CN, which was accompanied by a decrease of the surface area from 336 to $20 \mathrm{~m}^{2} / \mathrm{g}^{17}{ }^{17}$ during $\mathrm{Ag}_{3} \mathrm{PO}_{4} / \mathrm{C}_{3} \mathrm{~N}_{4}$ composite preparation, the surface area dropped from 23.2 to $0.2 \mathrm{~m}^{2} / \mathrm{g}$; ${ }^{14}$ deposition of $\mathrm{Ag} / \mathrm{AgCl}$ on carbon nitride resulted in a surface area decrease from $9.2 \mathrm{~m}^{2} / \mathrm{g}$ to $1.3 \mathrm{~m}^{2} / \mathrm{g}$. ${ }^{19}$

An alternative approach to introduce metals into the $\mathrm{C}_{3} \mathrm{~N}_{4}$ network, potentially even more homogeneous and also into the bulk of the material, comprises the addition of a metal salt during the synthesis of carbon nitride. ${ }^{5}$ Usually, also in this case, homogeneous metal distribution in the final product is not ensured, as a macroscopic demixing throughout the process might occur. Therefore, it is, in our opinion, crucial to select a suitable miscible and reactive metal precursor that would undergo co-condensation with the $\mathrm{C}_{3} \mathrm{~N}_{4}$ precursors in order to ensure homogeneity of the final composite. Metal cyanamides, dicyanamides, and tricyanomethanides are good candidates, but tricyanomethanides present three reactive cyano groups and a flat molecular geometry that potentially favors the incorporation into layered structures typical for $\mathrm{CN}$ polymers, as well as it is expected to bring extra electron density, favorable for reductive catalysis.
Catalyzed hydrogenations are fundamental reactions for academics and industry for the preparation of various platform chemicals. Pd-loaded carbon nitrides were reported to have promising catalytic activities for selective hydrogenation of phenols to the corresponding cyclohexanones, ${ }^{22-24}$ hydrogenation of quinoline to $1,2,3,4$-tretrahydroquinoline, ${ }^{25}$ partial hydrogenation of substituted phenylacetylenes to the corresponding styrenes, ${ }^{26}$ and many more. Compared to Pd, which is the most efficient known catalyst for this type of reaction, ${ }^{27}$ $\mathrm{Ag}$ represents a cheaper, less toxic, and less studied alternative. Recently, silver NPs loaded at different inorganic supports were evaluated in the three-phase partial hydrogenation of functionalized alkynes. The catalysts showed remarkable stereo- and chemoselectivity and benefits of low cost and operation at mild reaction conditions. ${ }^{28}$

Herein, we describe a strategy for simultaneous silver doping and introduction of negative charges into the carbon nitride $\mathrm{C}_{3} \mathrm{~N}_{4}$ network by using silver tricyanomethanide (AgTCM) as a reactive comonomer. The introduced negative charges beneficially contribute to the semiconductor structure of carbon nitrides and act as a strong binding site for the atomically distributed silver, promoting charge transport between the metal centers and semiconductor. We exemplify this effect via the application of different AgTCM-modified carbon nitrides in the photocatalytic water reduction and threephase alkyne hydrogenation. It is shown that the catalysts prepared with Ag tricyanomethanide possess indeed improved performance compared to that of conventionally prepared analogous silver materials in nanoparticulate form.

\section{RESULTS AND DISCUSSION}

The introduction of both silver ions and negatively charged centers into a $\mathrm{C}_{3} \mathrm{~N}_{4}$ network using silver tricyanomethanide as a comonomer was accomplished using co-condensation with 
a)

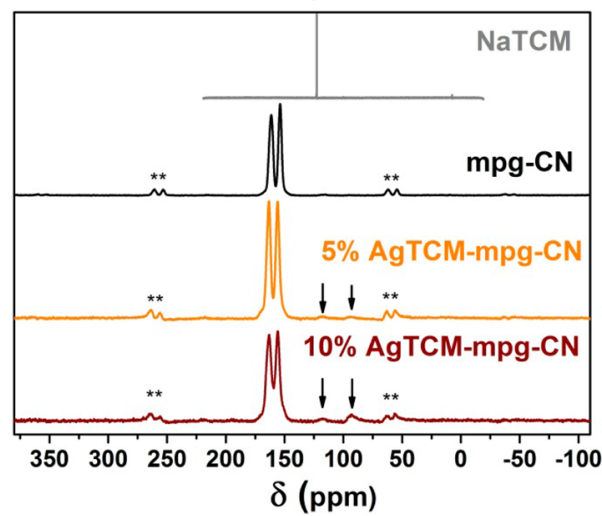

b)

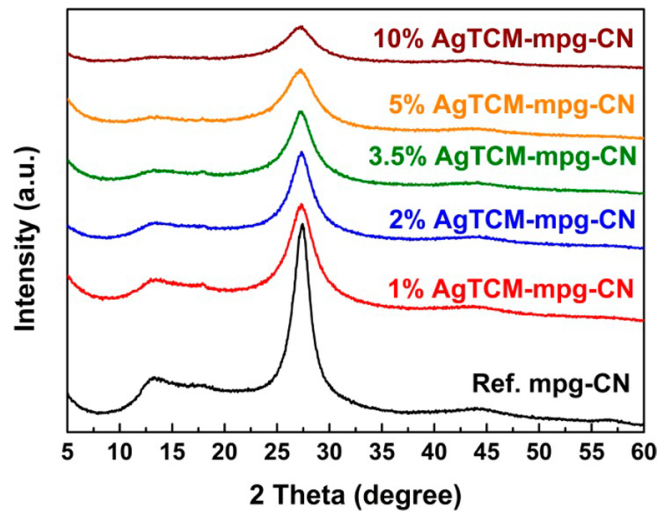

Figure $1 .{ }^{13} \mathrm{C}-{ }^{1} \mathrm{H} \mathrm{CP} / \mathrm{MAS}$ NMR spectra of mpg-CN, 5 and $10 \mathrm{wt} \% \mathrm{AgTCM}-\mathrm{mpg}-\mathrm{CN}$, and ${ }^{13} \mathrm{C}$ NMR spectrum of NaTCM in $\mathrm{D}_{2} \mathrm{O}$. Asterisks indicate spinning side bands in the ${ }^{13} \mathrm{C}$ spectra (a). PXRD patterns of the reference mpg-CN and the products prepared using different amounts of AgTCM (b).

a)

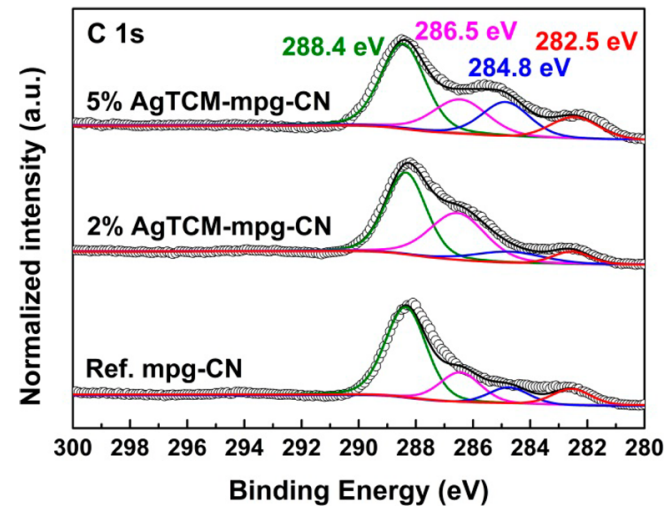

b)

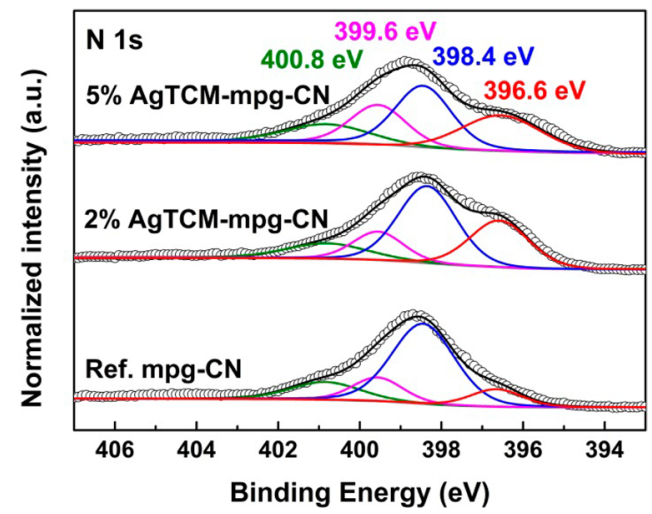

Figure 2. C 1s (a) and N 1s (b) XPS spectra of the reference mpg-CN, 2 and 5 wt \% AgTCM-mpg-CN.

cyanamide according to Scheme 1 . The behavior of the reaction mixture consisting of AgTCM and cyanamide (using a 1:6 molar ratio, according to the stoichiometry in Scheme 1) was observed by naked eye upon heating in a flask under nitrogen flow. First, cyanamide melts and slowly dissolves the tricyanomethanide to give a transparent yellow solution. After AgTCM is dissolved, a highly exothermic reaction takes place at about $80^{\circ} \mathrm{C}$, and the subsequent reactions proceed in a solid state. However, to avoid an excessive decrease of the useful band gap energy, smaller amounts of the dopant were used in the following synthetic protocols.

In order to develop a high surface area in the final products, which is desirable for most applications, we have used a $\mathrm{SiO}_{2}$ NP template (details on the synthetic procedure are given in the Materials and Methods section). Different quantities of silver tricyanomethanide, namely, 1, 2, 3.5, 5, and $10 \mathrm{wt} \%$ relative to the amount of cyanamide, were applied to successfully introduce the desired amounts of silver into the hybrid structure (Table S1).

The chemical structure of the final AgTCM-doped carbon nitrides is similar to that of the reference mesoporous graphitic carbon nitride (mpg-CN), ${ }^{29}$ prepared without dopant, as revealed by the ${ }^{13} \mathrm{C}$ solid-state cross-polarization/magic angle spinning nuclear magnetic resonance (CP/MAS NMR) spectra in Figure 1a. The two main $C$ signals at 163 and $156 \mathrm{ppm}$ in the silver-doped materials are attributed to $\mathrm{CN}_{2}\left(\mathrm{NH}_{x}\right)$ and $\mathrm{CN}_{3}$ moieties, respectively. ${ }^{30}$ Upon increase of the AgTCM concentration to 5 or 10 wt \%, additional C signals at 117 and $93 \mathrm{ppm}$ assigned to very electron rich, aromatic $\mathrm{sp}^{2}$ hybridized carbons start to develop, suggesting the successful incorporation of TCM fragments into the final polymer structure. The ${ }^{13} \mathrm{C}$ spectrum of the original tricyanomethanide anion shows mainly the contribution of cyano groups at 123 ppm, while the signal of negatively charged carbon is barely visible at $7.5 \mathrm{ppm}$.

The introduction of silver ions is accompanied by a slight disturbance of the local $\mathrm{C}_{3} \mathrm{~N}_{4}$ network structure. This is illustrated by the intensity decrease and broadening of the stacking reflection at $27^{\circ} 2 \theta$ in Figure $1 \mathrm{~b}$, suggesting the increased distortion of the stacking arrangement of the carbon nitride layers and the decrease of the crystallite size in the resulting products upon increase of the amount of AgTCM.

To further reveal the nature of the induced chemical changes in the $\mathrm{C}_{3} \mathrm{~N}_{4}$ network, we conducted X-ray photoelectron spectroscopy (XPS) investigations. In Figure 2, the $\mathrm{C} 1 \mathrm{~s}$ and $\mathrm{N}$ 1s spectra of 2 and 5 wt \% AgTCM-mpg-CN are compared to the corresponding spectra of the reference mpg-CN. In general, the $\mathrm{C} 1 \mathrm{~s}$ signals of all products (Figure $2 \mathrm{a}$ ) consist of four contributions, with binding energies of 288.4, 286.5, 284.8, and $282.5 \mathrm{eV}$. The first one is assigned to $\mathrm{CN}_{3}$ bonds in the tri-striazine ring, and the second one to hydroxylated surface carbon atoms $(\mathrm{C}-\mathrm{OH})$; the third one is due to adventitious carbon contamination as well as electron-rich $\mathrm{sp}^{2}$-hybridized carbons $(\mathrm{C}-\mathrm{C})$ in the case of AgTCM-modified products, 
while the last contribution suggests the presence of carbide-like carbon (highly negative carbons) in the samples. $\mathrm{N}$ 1s signals (Figure 2b) can be deconvolved into four peaks at $400.8 \mathrm{eV}$ $\left(\mathrm{NH}_{x}\right.$ groups), $399.6 \mathrm{eV}$ (tertiary nitrogens, $\mathrm{NC}_{3}$, corresponding to the $\mathrm{N}$ atoms in the center of the tri-s-triazine ring and in tertiary amide group bridging three tri-s-triazine units), 398.4 $\mathrm{eV}(\mathrm{C}-\mathrm{N}=\mathrm{C}$, ring nitrogen), and $396.6 \mathrm{eV}$ (negatively charged nitrogen atoms, $\mathrm{C}-\mathrm{N}^{\ominus}-\mathrm{C}$ ). The negative charge at nitrogen and carbon atoms at the surface of mpg-CN is more pronounced when adding the AgTCM: the weight of the $\mathrm{N} \mathrm{1s}$ contribution at $396.6 \mathrm{eV}$ relative to the weight of the main contribution at $398.4 \mathrm{eV}$ is 0.18 for mpg-CN, while in 2- and $5 \%$-doped products, it is 0.62 and 0.89 , respectively. On the other hand, in 5 wt \% AgTCM-mpg-CN, the weight of the $\mathrm{C}^{\ominus}$ contribution at $282.5 \mathrm{eV}$ relative to the weight of the main peak at $288.4 \mathrm{eV}$ is 0.30 , while it is only 0.20 in the reference mpg$\mathrm{CN}$.

We take the increased number of negatively charged carbon and nitrogen atoms in AgTCM-doped $\mathrm{CN}$ polymers as an indication for the successful incorporation of tricyanomethanide fragments into a joint electronic network. The fact that more negative charge is localized at nitrogen compared to carbon can be simply explained by its higher electronegativity, which influences the structure of the frontier orbitals. ${ }^{31}$ Interestingly, the amounts of the generated formal $\mathrm{N}^{\ominus}$ and $\mathrm{C}^{\ominus}$ centers greatly exceed those expected according to the quantities of the dopant used in the synthesis. Taking into account that some negatively charged species are characteristic also for the pristine mpg-CN, we suggest that the addition of the tricyanomethanide anion during the synthesis further enhances the tendency of the formation of negatively charged $\mathrm{CN}$ polymer structures, where the charges, of course, are delocalized and shared in the joint electron pool by a number of atoms. It will be shown that these negatively charged centers discussed above facilitate the subsequent deposition of metal nanoparticles at the surface of the solids and enhance their catalytic performance.

XPS investigations further confirmed the successful introduction of silver in the products. As shown in Figure S1a, the $\mathrm{Ag} 3 \mathrm{~d}$ signal consists of two contributions, a minor one of $\mathrm{Ag}^{+}$ at $365.8 \mathrm{eV}$ (for $3 \mathrm{~d}_{5 / 2}$ orbitals) and the major one of $\mathrm{Ag}^{0}$ at $367.9 \mathrm{eV}$, which is due to the ammonia-assisted thermal reduction of $\mathrm{Ag}^{+}$, but potentially also due to electron backdonation from the very electron rich semiconductor framework which can be understood as a macro-version of a ligand. The relative content of pro-forma $\mathrm{Ag}^{0}$ and $\mathrm{Ag}^{+}$estimated according to the areas of the corresponding contributions is 0.61 and 0.39 in $2 \mathrm{wt} \%$ AgTCM-mpg-CN and 0.68 and 0.32 in $5 \mathrm{wt} \%$ doped product, while absolute weight content of $\mathrm{Ag}$ in the surface layer of the samples was calculated as 1.32 and $3.48 \%$, respectively. In order to access the bulk distribution of $\mathrm{Ag}$, a surface layer of the 2 wt \% AgTCM-mpg-CN sample was removed by $\mathrm{Ar}^{+}$sputtering. It turned out that the $\mathrm{Ag}$ content in the bulk of the material is higher than that at the surface, and that $\mathrm{Ag}^{+}$ions prevail over $\mathrm{Ag}^{0}$ (Figure S1a). The enrichment of $\mathrm{Ag}$ in the bulk of the products explains the apparent differences in the values of Ag content determined by energy-dispersive Xray spectroscopy (EDS) and XPS measurements (Table S1). Besides, all the products contain some oxygen, presumably originating mainly from the aqueous workup (Table S1). The O 1s signal consists of the three contributions at 529.4, 531.0, and $532.5 \mathrm{eV}$ due to deprotonated oxygen atoms, surface hydroxyl groups, and surface-adsorbed water, respectively
(Figure $\mathrm{S} 1 \mathrm{~b}$ ). The contribution of $\mathrm{O}^{\ominus}$ ions increases upon an increase of the AgTCM doping level in the materials; however, taking into account that the total oxygen content in the products is much lower than the sum of nitrogen and carbon content, we expect that the impact of $\mathrm{O}^{\ominus}$ groups has minor relevance compared to those of $\mathrm{N}^{\ominus}$ and $\mathrm{C}^{\ominus}$.

High-angle annular dark-field scanning transmission electron microscopy (HAADF-STEM) investigations performed on an aberration-corrected microscope showed the presence of silver in an atomically dispersed form throughout the samples, clearly seen due to the atomic number $(Z)$ contrast (Figure 3a; see
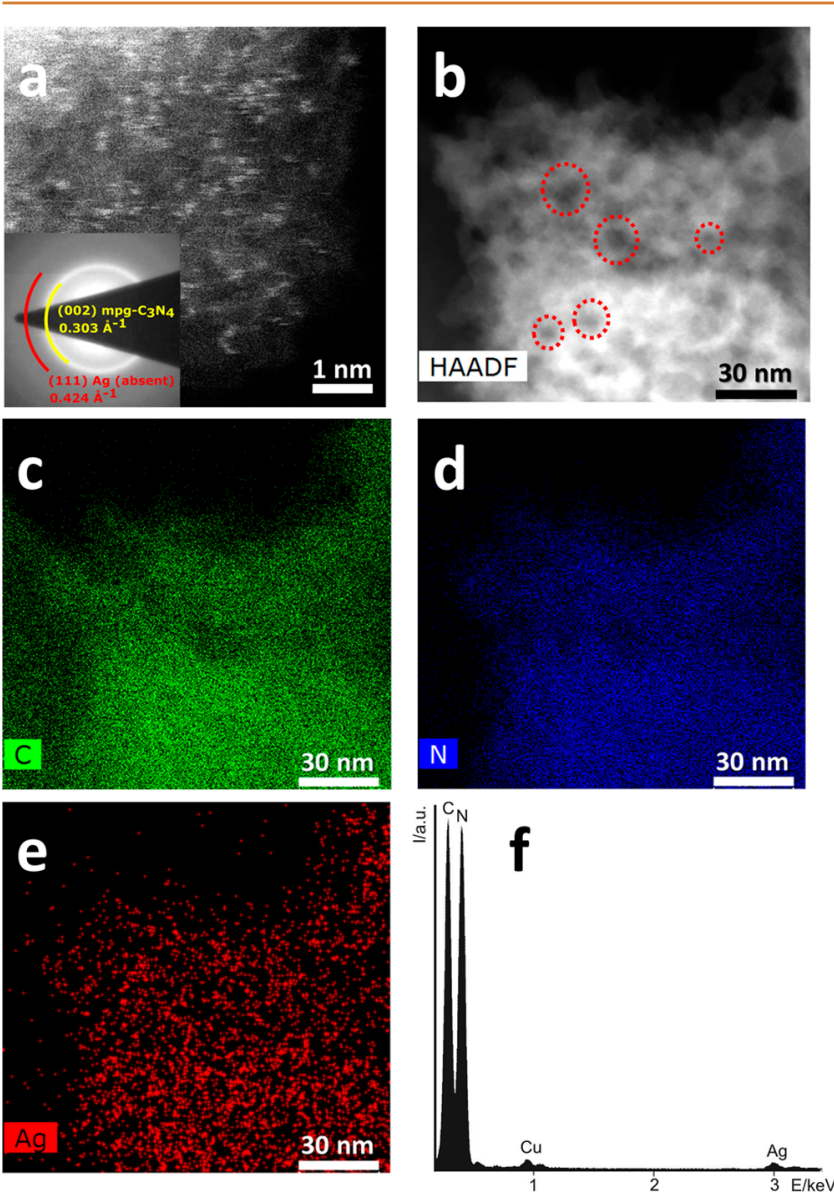

Figure 3. (a) Aberration-corrected HAADF-STEM image of the 1 wt \% AgTCM-mpg-CN, showing isolated single Ag atoms distributed across the mpg-CN support. Inset: Diffraction pattern from this sample. (b) Low-magnification HAADF-STEM image (a few selected mesopores are indicated by dashed circles) along with C (c), N (d), and Ag (e) EDS mapping of 2 wt \% AgTCM-mpg-CN. EDS spectrum extracted from the map data. The $\mathrm{Cu}$ peak is due to the material of the TEM grid (f).

also Figure S2). The absence of diffraction rings corresponding to crystalline Ag (inset Figure 3a) gives further verification that $\mathrm{Ag}$ atoms are ubiquitously dispersed and not in the form of nanoparticles. This is additionally supported by the HAADFSTEM image obtained on a standard microscope along with EDS mapping of $\mathrm{C}, \mathrm{N}$, and $\mathrm{Ag}$, which shows the homogeneous distribution of these elements (Figure $3 \mathrm{~b}-\mathrm{e}$ ). The energydispersive X-ray spectrum retrieved from the collected data of these maps (Figure 3f) confirms the presence of all relevant elements in this area. No regions of pronounced local intensity are seen in the Ag map (Figure 3e), verifying the absence of 
nanoparticles. Instead, $\mathrm{Ag}$ is detected to be nearly uniformly distributed across the mpg-CN support. It is remarkable that, upon increase of silver content in the products, no major $\mathrm{Ag}$ NPs are detected, as shown by the analysis of $10 \mathrm{wt} \%$ AgTCMmpg-CN (see Figure S3). Additionally, the HAADF-STEM micrographs enable visualization of the characteristic mesopores of 5-25 nm of the solids, in line with the results of $\mathrm{N}_{2}$ physisorption studies (see below).

$\zeta$-Potential measurements also reflect the influence of the introduced negatively charged centers on the surface properties of the prepared solids. The isoelectric point (IEP) of reference mpg-CN is found to be 2.56 , which is usually attributed to the presence of the surface hydroxyl groups $(\mathrm{C}-\mathrm{OH})$ that are highly acidic and dissociate in water to give surface $\mathrm{O}^{\ominus}$ ions. ${ }^{32,33}$ Upon increasing the AgTCM content, the isoelectric point of the corresponding products, however, shifts to even lower values, and the IEP can be as low as 1.83 for $10 \mathrm{wt} \%$ AgTCM-mpg-CN (Figure S4). We attribute that to the strongly stabilized negative charge on the structure which cannot be easily neutralized by protons, which can also be described as an increased, presumably nonlocalized, basicity of the surface.

One nearby advantage of the described TCM doping method over the already reported approaches is that the AgTCM-doped products possess up to 1.5 times higher surface areas compared to the reference mpg- $\mathrm{CN}$, as delineated in Table 1 and Figure

Table 1. Physical and Textural Properties of the Reference mpg-CN and AgTCM-Doped Products as Well as Measured Hydrogen Evolution Rates of These Materials

\begin{tabular}{lccccc}
\multicolumn{1}{c}{ product } & $\begin{array}{c}S_{\mathrm{BEE}}{ }^{a} \\
\left(\mathrm{~m}^{2} / \mathrm{g}\right)\end{array}$ & $\begin{array}{c}V_{\text {pore }}{ }^{b} \\
\left(\mathrm{~cm}^{3} / \mathrm{g}\right)\end{array}$ & $\begin{array}{c}V_{\text {micro }}{ }^{c} \\
\left(\mathrm{~cm}^{3} / \mathrm{g}\right)\end{array}$ & $\begin{array}{c}\mathrm{BG}^{d} \\
(\mathrm{eV})\end{array}$ & $\begin{array}{c}\mathrm{HER}^{e} \\
(\mu \mathrm{mol} / \mathrm{h})\end{array}$ \\
ref mpg-CN & 119 & 0.223 & 0.007 & 2.78 & 9.8 \\
1\% AgTCM-mpg-CN & 193 & 0.354 & 0.009 & 2.79 & 35.5 \\
2\% AgTCM-mpg-CN & 157 & 0.510 & 0.009 & 2.78 & 39.5 \\
3.5\% AgTCM-mpg-CN & 206 & 0.759 & 0.010 & 2.75 & 36.9 \\
5\% AgTCM-mpg-CN & 190 & 0.690 & 0.010 & 2.73 & 29.2 \\
10\% AgTCM-mpg-CN & 188 & 0.676 & 0.009 & 2.67 & 21.2
\end{tabular}

${ }^{a}$ Total surface area. ${ }^{b}$ Pore volume at $p / p_{0}=0.95 .{ }^{c}$ The $t$-plot method. ${ }^{d}$ Optical band gap. ${ }^{e}$ Measured hydrogen evolution rate.

4a. The increase of the surface areas is accompanied by the increase of the pore volumes, resulting from the increased size of the generated pores as suggested by the slight shift of the hysteresis onset in the corresponding nitrogen sorption isotherms to higher $p / p_{0}$ as well as by the results of pore size analysis (Figure $4 \mathrm{a}, \mathrm{b}$ ). AgTCM-doped products are characterized by more homogeneous pore size distribution than the reference mpg-CN that follows from almost vertical inclination of the sorption curves at $p / p_{0}=0.65-0.95$ and points out the beneficial effect of silver doping. There is a minor development of microporosity when silver is introduced in the materials. Tentatively, this could be related to the disturbance of the local carbon nitride network structure by the Ag species or to the stabilization of micropores by Ag species, but understanding of the phenomenon is beyond the scope of the present contribution.

The influence of the negatively charged species on the electronic properties of the $\mathrm{C}_{3} \mathrm{~N}_{4}$ structure introduced by TCM doping was examined by optical spectroscopy, electrochemical impedance spectroscopy, and Mott-Schottky analysis. First, the controlled insertion of carbon-carbon bonds (Scheme 1) enables the tuning of the visible light absorption properties of the resulting $\mathrm{CN}$ polymers and their optical band gap values, as shown in Figure 5a: with increasing AgTCM concentration, the visible light absorption threshold shifts slightly to longer wavelengths. Furthermore, the successful introduction of silver species and partial negative charges into the carbon nitride network results in an increase of the steady-state photoluminescence (PL) for almost all of the products (Figure $5 \mathrm{~b}$ ). A clear red shift is observed in the emission spectra, and it gets more pronounced with increasing dopant quantity. At the same time, PL lifetime is almost unaltered, as shown in Figure S5, for the comparison of the $3.5 \mathrm{wt} \%$ AgTCM-doped product and the reference mpg-CN. Such a combination illustrates a change of the semiconductor behavior which is rather untypical for the conventional CN polymers, where the reported structural defects are mainly deep-level traps at which nonradiative recombination occurs, and the decrease of PL lifetime is accompanied by a decrease of the steady-state PL. ${ }^{34}$ One might speculate that the red-shifted states introduced by doping promote recombination of electrons and holes by their colocalization at the silver centers due to tighter binding. The significant decrease of PL upon increasing AgTCM concentration to $10 \mathrm{wt} \%$ is caused by introduction of lattice defects, as corroborated by PXRD investigations.

Despite the induced chemical modifications, Mott-Schottky analysis indicated that the absolute values of flat-band potentials a)

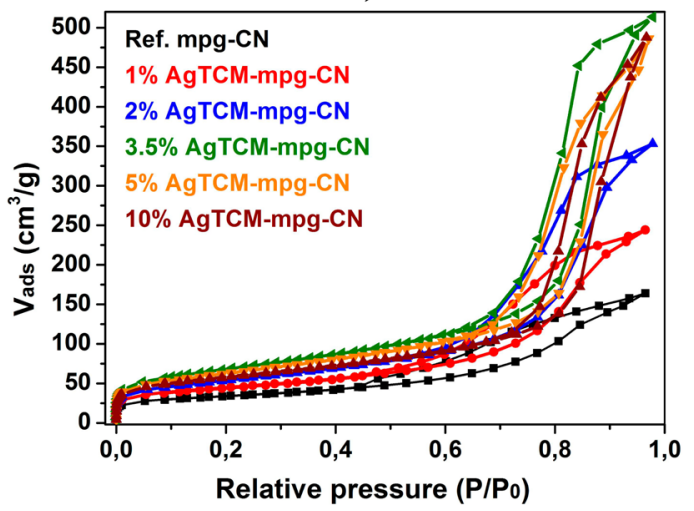

b)

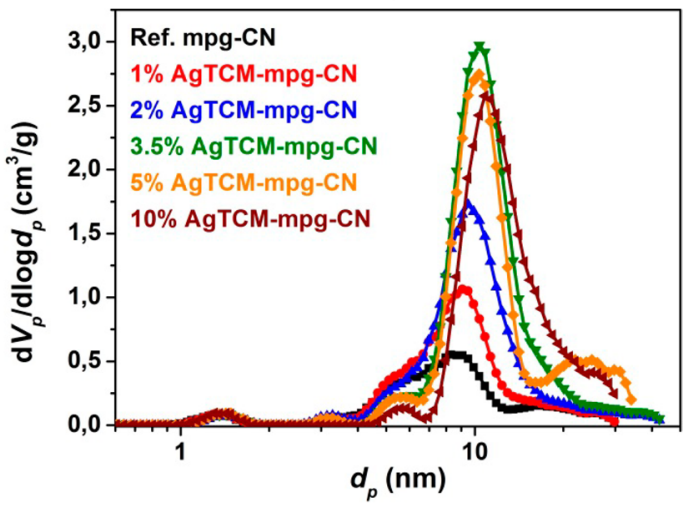

Figure 4. Nitrogen sorption isotherms at $77 \mathrm{~K}$ (a) and corresponding pore size distribution calculated by a nonlocal density functional theory model assuming slit-shaped pores (b) of the reference mpg-CN and Ag-containing materials. 

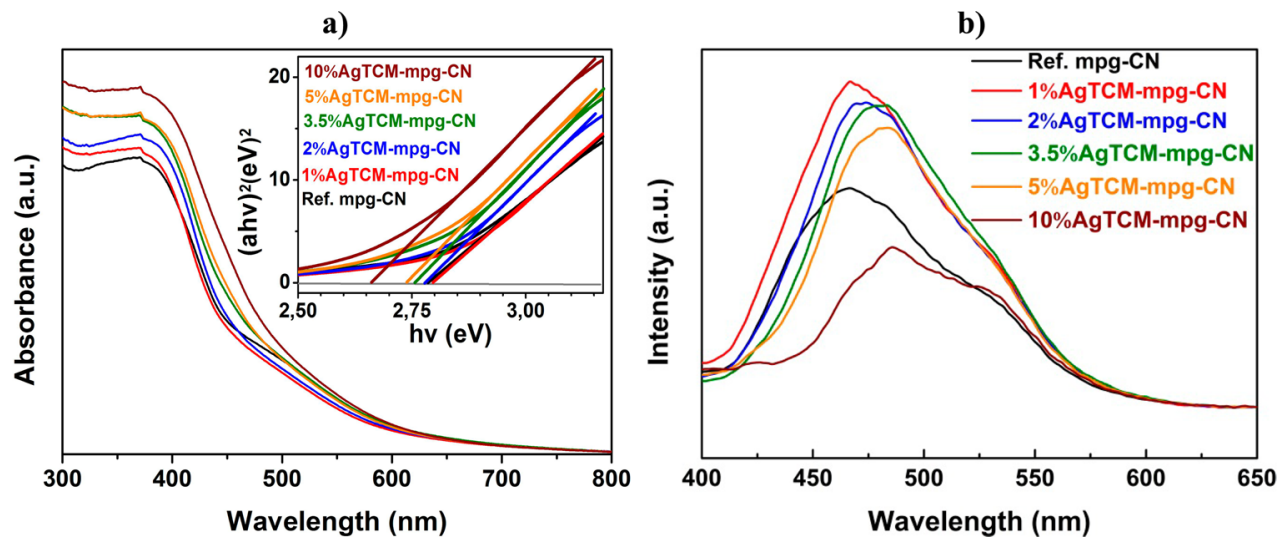

Figure 5. UV-vis absorption spectra of AgTCM-doped products illustrating improvement of visible light absorption upon increasing amount of the dopant (a); emission spectra of the reference mpg-CN and AgTCM-doped products excited at $350 \mathrm{~nm}$ (b).
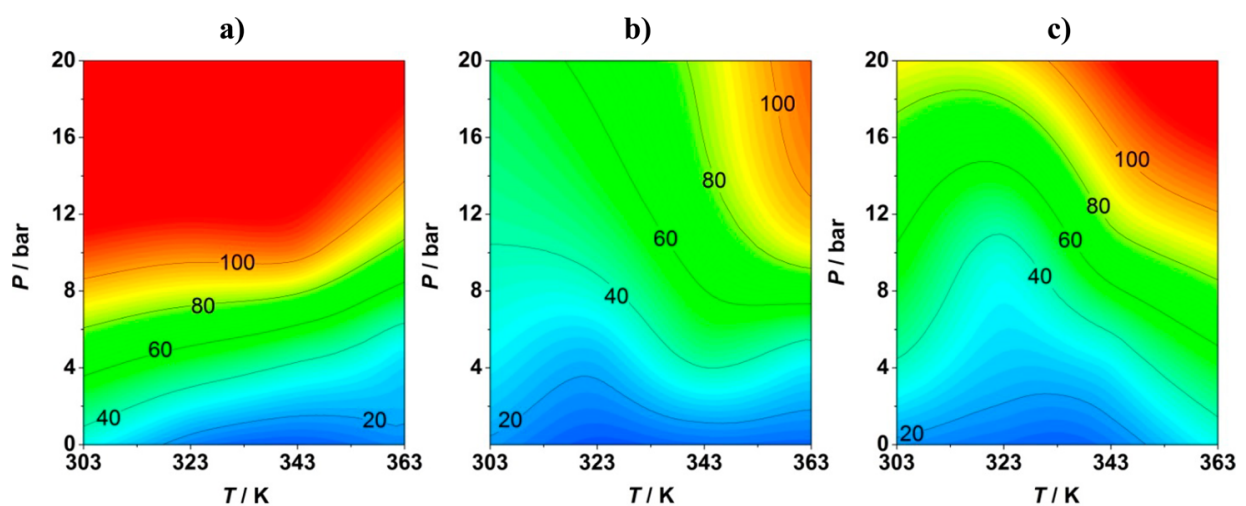

Figure 6. Rate of 1-hexyne hydrogenation (in $\mathrm{mol}_{\text {alkyne }} \mathrm{h}^{-1} \mathrm{~mol}_{\mathrm{Ag}}{ }^{-1}$ ) at different temperatures and pressures over AgTCM-mpg-CN (a), Agmpg-CN-SD (b), and Ag-mpg-CN-IR (c). Reaction conditions: $W_{\text {cat }}=200 \mathrm{mg}, F(1$-hexyne + toluene $)=1 \mathrm{~cm}^{3} \mathrm{~min}^{-1}, F\left(\mathrm{H}_{2}\right)=36 \mathrm{~cm}^{3} \mathrm{~min}^{-1}$. The selectivity to 1 -hexene was $100 \%$ in all three cases.

of AgTCM-doped products are very close to that of the reference mpg-CN (which is about $-0.83 \mathrm{eV}$ on the $\mathrm{RHE}$ scale). This might be due to the compensation of the effects of $\mathrm{Ag}^{+}$introduced mainly to the bulk of products (as supported by ${ }^{13} \mathrm{C}$ NMR and Ag 3d XPS spectra after bombardment) by negatively charged nitrogen and carbons located preferentially in the surface layer (as seen from $\zeta$-potential values and $\mathrm{C} 1 \mathrm{~s}$ and $\mathrm{N}$ 1s XPS spectra). All samples showed a positive slope in the linear Mott-Schottky plots (Figure S6a), which is characteristic for n-type semiconductors and goes well with the excess negative charges on the semiconductor framework. This suggests that the found values of flat-band potentials approximately correspond to the conduction band positions of the materials. The positions of the valence bands were estimated by subtraction of the optical band gap values from the flat-band potentials; the obtained results are indicated in Figure S6b.

As a result of superposition of favorable material properties provided by TCM doping, namely, increased surface areas, created negatively charged surface sites for charge exchange, and despite lower X-ray structural order, AgTCM-mpg-CN products show an activity in the Pt-assisted photocatalytic water reduction up to 4 times higher than that of the reference mpgCN sample (Figure S7a and Table 1). The detailed description of the experimental procedure is given in the Materials and Methods section. In the beginning of the sacrificial water reduction experiments, hexachloroplatinic acid is added and photoreduced, yielding Pt NPs that are in situ deposited on the electron exit sites of the surface of the photocatalyst. EDS investigations of the photocatalysts after hydrogen evolution reaction showed that the amount of $\mathrm{Pt}$ deposited at the surface of $3.5 \%$ AgTCM-mpg-CN is $1.47 \mathrm{wt} \%$, which is 2 -fold higher than the Pt amount deposited at mpg-CN (0.71 wt \%). The highest activity of $39.5 \mu \mathrm{mol} \mathrm{H}_{2} / \mathrm{h}$ is observed for $2 \mathrm{wt} \%$ AgTCM-mpg-CN (the value for the reference mpg-CN is 9.8 $\mu \mathrm{mol} \mathrm{H}_{2} / \mathrm{h}$ ). Further increase of the dopant concentration obviously leads to more significant distortion of the semiconductor lattice, resulting in the decrease of the photocatalytic reaction rates. Pristine AgTCM-mpg-CN photocatalysts without Pt particles are able to reduce water, as well, though with much lower reaction rates compared to Pt-loaded ones. For example, $3.5 \mathrm{wt} \%$ AgTCM-mpg-CN produces $1.25 \mu \mathrm{mol} \mathrm{H}_{2} / \mathrm{h}$ (Figure S7b).

Finally, we assessed the catalytic performance of the AgTCM-doped material ( 1 wt \% Ag) in the continuous-flow three-phase semihydrogenation of 1 -hexyne, a model reaction for processes used in the manufacture of fine chemicals and pharmaceutical intermediates. ${ }^{35}$ For comparison, 1 wt \% Agloaded mesoporous carbon nitrides prepared by conventional techniques such as spray deposition (coded Ag-mpg-CN$\mathrm{SD})^{28,36}$ and impregnation-chemical reduction (coded Agmpg-CN-IR) were evaluated, as well. Details on the preparation and characterization of the latter solids can be found in the Materials and Methods section and in Table S2 (Supporting Information), respectively. In general, these two materials exhibited truncated octahedral-shaped nanoparticles, exposing 
(111) and (100) faces, with an average diameter of approximately $5 \mathrm{~nm}$.

The contour plots in Figure 6 depict the results of the catalytic tests. The AgTCM-doped material is by far the most active catalyst. For example, at $303 \mathrm{~K}$ and $10 \mathrm{bar}$, the reaction rate exceeds $100 \mathrm{~mol}_{\text {alkyne }} \mathrm{h}^{-1} \mathrm{~mol}_{\mathrm{Ag}}{ }^{-1}$ over the AgTCM-doped sample (Figure 6a), while it is ca. 40 and 60 mol $_{\text {alkyne }} \mathrm{h}^{-1}$ $\mathrm{mol}_{\mathrm{Ag}}^{-1}$ over the materials prepared by spray deposition and impregnation-reduction, respectively (Figure $6 \mathrm{~b}, \mathrm{c}$ ). The activity of AgTCM-mpg-CN exceeds, as well, that of the $\mathrm{Ag}$ catalysts reported in the literature (e.g., 1 wt \% $\mathrm{Ag} / \mathrm{TiO}_{2}$, average silver particle diameter $=5 \mathrm{~nm}),{ }^{36}$ which yielded $c a .30$ $\mathrm{mol}_{\text {alkyne }} \mathrm{h}^{-1} \mathrm{~mol}_{\mathrm{Ag}}{ }^{-1}$ at the same conditions. Accordingly, it can be concluded that the extremely high dispersion of the silver atoms in the single-site AgTCM-mpg-CN catalyst leads to a superior catalyst compared to the materials where silver is stabilized as nanoparticles (the latter exposed less surface to the reaction medium per mole of metal). In addition to its remarkable activity, the doped catalyst exhibits also a selectivity of $100 \%$ to the desired olefin at all conditions investigated. This is expected for silver catalysts, due to their ability to prevent overhydrogenation and isomerization pathways. ${ }^{36}$ Table 2

Table 2. Comparison of Heterogeneous Catalysts in the Semihydrogenation of 1-Hexyne

\begin{tabular}{lccc}
\multicolumn{1}{c}{ catalyst } & $\begin{array}{c}\text { metal } \\
\text { loading } \\
(\text { wt } \%)\end{array}$ & $\begin{array}{c}\text { rate } \\
\left(\text { mol }_{\text {product }} \mathrm{h}^{-1} \text { mol }_{\text {metal }}{ }^{-1}\right)\end{array}$ & $\begin{array}{c}S(1 \text {-hexene }) \\
(\%)\end{array}$ \\
\hline AgTCM-mpg-CN $^{a}$ & 1 & 103 & 100 \\
Ag-mpg-CN-SD & 1 & 39 & 100 \\
$\mathrm{Ag} / \mathrm{TiO}_{2}{ }^{a, 28}$ & 1 & 32 & 100 \\
$\mathrm{Pd}-\mathrm{Pb} / \mathrm{CaCO}_{3}{ }^{b, 37}$ & 1 & 101 & 98 \\
$\mathrm{Pd}-\mathrm{mpg}_{-}-\mathrm{CN}^{b, 37}$ & 5 & 578 & 100 \\
$\mathrm{Au} / \mathrm{TiO}_{2}{ }^{c, 28}$ & 1 & 41 & 97 \\
$\mathrm{CeO}_{2} / \mathrm{TiO}_{2}{ }^{d, 38}$ & 16 & 2 & 100
\end{tabular}

${ }^{a} W_{\text {cat }}=200 \mathrm{mg}, T=303 \mathrm{~K}, P=10 \mathrm{bar}, F(1$-hexyne + toluene $)=1 \mathrm{~cm}^{3}$ $\mathrm{min}^{-1}, F\left(\mathrm{H}_{2}\right)=36 \mathrm{~cm}^{3} \mathrm{~min}^{-1} \cdot{ }^{b} W_{\text {cat }}=100 \mathrm{mg}, T=303 \mathrm{~K}, P=1 \mathrm{bar}$, $F(1$-hexyne + toluene $)=1 \mathrm{~cm}^{3} \mathrm{~min}^{-1}, F\left(\mathrm{H}_{2}\right)=24 \mathrm{~cm}^{3} \mathrm{~min}^{-1} \cdot{ }^{c} W_{\text {cat }}=$ $100 \mathrm{mg}, T=373 \mathrm{~K}, P=10 \mathrm{bar}, F(1$-hexyne + toluene $)=1 \mathrm{~cm}^{3} \mathrm{~min}^{-1}$, $F\left(\mathrm{H}_{2}\right)=36 \mathrm{~cm}^{3} \mathrm{~min}^{-1} .{ }^{d} W_{\text {cat }}=850 \mathrm{mg}, T=363 \mathrm{~K}, P=40 \mathrm{bar}, F(1-$ hexyne + toluene $)=0.3 \mathrm{~cm}^{3} \mathrm{~min}^{-1}, F\left(\mathrm{H}_{2}\right)=36 \mathrm{~cm}^{3} \mathrm{~min}^{-1}$.

compares the performance of AgTCM-mpg-CN with a number of benchmark heterogeneous catalysts for the semihydrogenation of 1-hexyne. The single-atom silver catalyst is superior to supported $\mathrm{CeO}_{2}$ and $\mathrm{Au}$ nanoparticles, and it is even competitive with the archetypical Lindlar catalyst $(\mathrm{Pd}-\mathrm{Pb}$ / $\mathrm{CaCO}_{3}$ ). We have also included the recently reported Pd-mpg$\mathrm{CN},{ }^{37}$ which comprises single palladium atoms stabilized on the carbon nitride structure. The latter is $c a$. 6 times more active than the silver analogue, which comes as no surprise following the much easier $\mathrm{H}_{2}$ splitting on $\mathrm{Pd}$ compared to Ag.

At this point, we should note that, compared to the reported preparation of carbon nitride supported single-atom-dispersed $\mathrm{Pd}$ by an impregnation-chemical reduction procedure, ${ }^{37}$ the metal tricyanomethanide copolymerization approach offers the following advantages: first, the introduction of negatively charged $\mathrm{C}$ and $\mathrm{N}$ atoms in the $\mathrm{C}_{3} \mathrm{~N}_{4}$ network (Scheme 1) enables better dispersion of metal species (as metal atoms, ions, or clusters) in the products. Even at $10 \mathrm{wt} \%$ dopant concentration, no agglomeration of Ag to Ag NPs was detected in the products. The introduction of similar metal amounts by the impregnation-chemical reduction procedure leads to the formation of metal NPs due to insufficient stabilization of single metal atoms/ions by the support. ${ }^{23}$ Furthermore, the TCMcopolymerization approach enables one to obtain materials having a joint electronic system and thus featuring very unusual hybrid material properties (e.g., increased PL). The use of the reactive precursor and the fact that AgTCM is soluble in molten cyanamide ensures homogeneity of metal distribution within the products. Finally, in contrast to the impregnationchemical reduction procedure, the suggested method of metal introduction leads to products with a $50 \%$ increase of BET surface areas compared to that of the reference (nondoped) mpg-CN.

Table 2 clearly demonstrates that single-atom catalysts show enhanced reactivity compared to nanoparticle-based catalysts as a consequence of their dispersion of the active phase, leading to a very high metal utilization in the catalytic process. A singlesite silver catalyst competes with a conventional nanoparticulate palladium catalyst in terms of reactivity and selectivity (see Table 2 to compare the performance of AgTCM-mpg-CN with that of $\mathrm{Pd}-\mathrm{Pb}$ ). For a silver catalyst comprising silver nanoparticles, such competitive performance is not observed (see Table 2 to compare the performance of Ag-mpg-CN-SD with that of $\mathrm{Pd}-\mathrm{Pb}$ ). Thus, by creating single-atom catalytic centers, an intrinsically unreactive metal such as silver can approach the activity of the most active hydrogenation catalyst (i.e., Pd-based). It should be also taken into account that $\mathrm{Ag}$ is much cheaper than Pd.

The role of the negatively charged carbon nitride support in the catalytic cycle (e.g., partaking in $\mathrm{H}_{2}$ splitting and/or alkyne adsorption) can also contribute to this improved performance. However, blank experiments over the silver-free carbon nitride revealed its complete inactivity under the studied experimental conditions, emphasizing the primary role of the silver atoms in the observed catalytic behavior. Future studies should carefully address the nature of the active silver species in the reaction. XPS analyses have demonstrated two different states of silver (metallic and charged atoms). $\mathrm{Ag}^{\mathrm{O}}$ is often regarded as the active hydrogenation phase. ${ }^{28,36}$ However, our recent communication dealing with atomic Pd stabilized on mesoporous carbon nitride hinted a possible beneficial contribution of charged atoms in alkyne hydrogenation. ${ }^{37}$ Discriminating between the relative importance of the metallic/ionic state of silver (or a different atom) in the hydrogenation process is beyond the scope of this paper and would require dedicated operando spectroscopic investigations. Detailed density functional theory analyses of the reaction mechanism over these cationic-anionic polarized surface patterns of the carbon nitride support will also contribute to further understand these intriguing materials.

\section{CONCLUSION}

The modification of a carbon nitride structure by doping with silver tricyanomethanide leads to the creation of extra negatively charged/polarized carbon and nitrogen centers, neutralized by silver ions, which are atomically dispersed within the structure. All applied techniques indicate that silver plays the role of a highly efficient dopant for carbon nitride and gets hybridized into the resulting electronic network with a shared electron orbital structure. The obtained solids possess comparably high surface areas and are characterized by homogeneous distribution of silver present as atomic dispersion in the final products. The usefulness of this material was illustrated in two applications: the photoassisted water 
reduction (after further Pt NP deposition) and the selective hydrogenation of 1-hexyne. The simultaneous insertion of a metal species from a TCM precursor, if combined with a proper selection of the reaction atmosphere (inert, oxidative, or reductive), is expected to be a general way to prepare various single-site metal-supported organocatalysts for diverse applications.

\section{MATERIALS AND METHODS}

Materials. Cyanamide (99\%), silver nitrate $\left(\mathrm{AgNO}_{3}, 99 \%\right)$, LUDOX HS-40 colloidal silica, ammonium hydrogen difluoride $\left(\mathrm{NH}_{4} \mathrm{HF}_{2}, 99 \%\right)$, and hexachloroplatinic acid $\left(\mathrm{H}_{2} \mathrm{PtCl}_{6}\right)$ solution (8 wt $\%$ aqueous solution) were purchased from Sigma-Aldrich, and triethanolamine (98\%) was purchased from Alfa Aesar. Sodium tricyanomethanide (NaTCM) was received as a gift from Lonza AG. All chemicals were of analytical grade and used without further purification.

Synthesis of Silver Tricyanomethanide. NaTCM (6.005 g, 53.1 mmol) was dissolved in $12 \mathrm{~mL}$ of water (solution 1 ), and $9.106 \mathrm{~g}$ of $\mathrm{AgNO}_{3}(53.1 \mathrm{mmol})$ was dissolved in $18 \mathrm{~mL}$ of water (solution 2); solutions were heated to $80{ }^{\circ} \mathrm{C}$ in a preheated oven. Afterward, hot solution 2 was added to hot solution 1 dropwise under vigorous stirring, and then the reaction flask was wrapped with $\mathrm{Al}$ foil and left upon agitation overnight at room temperature. The obtained white precipitate was filtered off, rinsed with deionized water, and then dried at $60^{\circ}$ under vacuum $(0.5 \mathrm{mbar})$.

Synthesis of AgTCM-mpg-CN. The AgTCM-doped mpg-CN samples were prepared by dispersing $1250 \mathrm{mg}(29.4 \mathrm{mmol})$ of cyanamide and different amounts of $\operatorname{AgTCM}(12.5,25,43.8,62.5$, and $125 \mathrm{mg}$ for 1, 2, 3.5, 5, and $10 \mathrm{wt} \%$ AgTCM-mpg-CN samples) in 2$3 \mathrm{~mL}$ of water. Then, appropriate amounts of a $40 \%$ dispersion of 12 $\mathrm{nm}$ colloidal silica (LUDOX HS-40) were added, and reagent mixtures were stirred at $100{ }^{\circ} \mathrm{C}$ for several hours to evaporate water. The weight ratio between precursors and silica was always fixed to 1:1. The resultant white powder was ground thoroughly and then heated to 550 ${ }^{\circ} \mathrm{C}$ at a heating rate of $2.3{ }^{\circ} \mathrm{C} / \mathrm{min}$ and maintained for $4 \mathrm{~h}$ at $550{ }^{\circ} \mathrm{C}$ under a flow of nitrogen $(15 \mathrm{~L} / \mathrm{min})$. The obtained brown-yellow powders were washed with $4 \mathrm{M} \mathrm{NH}_{4} \mathrm{HF}_{2}$ solution for $48 \mathrm{~h}$ to remove the silica template. Afterward, the powders were filtered, washed with water and ethanol several times until neutral $\mathrm{pH}$, and finally dried under vacuum $(10 \mathrm{mbar})$ at $50{ }^{\circ} \mathrm{C}$ overnight. The reference mpg-CN was prepared by the same procedure but without using AgTCM.

The reference mesoporous graphitic carbon nitride (mpg-CN) was prepared in exactly the same way and under the same conditions but without using AgTCM. The preparation procedure is described elsewhere. ${ }^{29}$

Synthesis of 1 wt \% Ag-mpg-CN by an ImpregnationReduction Method (Ag-mpg-CN-IR). Typically, $2 \mathrm{~g}$ of mpg-CN was dispersed in $200 \mathrm{~mL}$ of deionized (DI) water under sonication for $30 \mathrm{~min}$. Then $31.5 \mathrm{mg}$ of $\mathrm{AgNO}_{3}$ was added into the suspension for impregnation, followed by another $30 \mathrm{~min}$ sonication. Afterward, 5.6 $\mathrm{mL}$ of freshly prepared $0.5 \mathrm{M} \mathrm{NaBH}_{4}$ solution in DI water was added into the suspension under vigorous stirring. The reaction mixture was agitated overnight. The final $1 \%$ Ag-mpg-CN-IR was separated by filtration, washed with DI water and ethanol thoroughly, and dried under vacuum (10 mbar) at $50{ }^{\circ} \mathrm{C}$.

Synthesis of 1 wt \% Ag-mpg-CN by Spray Deposition (Agmpg-CN-SD). ${ }^{39}$ The preparation was carried out in a Büchi mini spray dryer B-290 equipped with a two-fluid nozzle with a $1.4 \mathrm{~mm}$ diameter. This technique allows the deposition of metal (oxide) particles with a high degree of dispersion. Silver nitrate $(0.01 \mathrm{~g})$ was dissolved in $20 \mathrm{~cm}^{3}$ of DI water under magnetic stirring at room temperature, followed by addition of the support (mpg-CN, $1 \mathrm{~g})$. The resulting suspension was pumped at $3 \mathrm{~cm}^{3} \mathrm{~min}^{-1}$ into the two-fluid nozzle, together with a spray air flow of $0.5 \mathrm{~m}^{3} \mathrm{~h}^{-1}$, creating droplets of $20-30 \mu \mathrm{m}$. The inlet temperature was set at $493 \mathrm{~K}$, the aspiration rate at $35 \mathrm{~m}^{3} \mathrm{~h}^{-1}$, and the outlet temperature at $383 \mathrm{~K}$. The dried particles were separated using a cyclone and activated in 5 vol $\% \mathrm{H}_{2} / \mathrm{N}_{2}(20$ $\mathrm{cm}^{3} \mathrm{~min}^{-1}$ ) at $473 \mathrm{~K}$ for $30 \mathrm{~min}$.
Photocatalytic Hydrogen Evolution Tests. Reactions were performed using a side-irradiated closed steel reactor equipped with a Teflon inlet, thermocouple, pressure sensor, magnetic stirring, and thermostat and connected to a Schlenk line. $\mathrm{H}_{2}$ production was carried out using $50 \mathrm{mg}$ of catalyst dispersed in $38 \mathrm{~mL}$ of solvent mixture composed of triethanolamine and water in the ratio of $1 / 9(\mathrm{v} / \mathrm{v})$. Pt nanoparticles ( $3 \mathrm{wt} \%$ ) were deposited on carbon nitrides by an in situ photodeposition procedure using hexachloroplatinic acid $\left(\mathrm{H}_{2} \mathrm{PtCl}_{6}\right)$ solution as a precursor. The buildup of $\mathrm{H}_{2}$ pressure was monitored as a function of the irradiation time. The irradiation source was a $50 \mathrm{~W}$ white LED array (Bridgelux BXRA-50C5300, $\lambda>410 \mathrm{~nm}$ ). The detailed description of the setup and the test procedure can be found in the literature. ${ }^{40}$

Characterization. Powder X-ray diffraction patterns were measured on a Bruker D8 Advance diffractometer equipped with a scintillation counter detector with $\mathrm{Cu} \mathrm{K} \alpha$ radiation $(\lambda=0.15418 \mathrm{~nm})$ applying a $2 \theta$ step size of $0.05^{\circ}$ and counting time of $4 \mathrm{~s}$ per step. The solid-state NMR ${ }^{13} \mathrm{C}\left\{{ }^{1} \mathrm{H}\right\} \mathrm{CP} /$ MAS (cross-polarization magic angle spinning) measurements were carried out using a Bruker Avance 400 spectrometer operating at $100.6 \mathrm{MHz}$ using a Bruker $4 \mathrm{~mm}$ doubleresonance probe head operating at a spinning rate of $10 \mathrm{kHz} .{ }^{1} \mathrm{H}$ composite pulse decoupling was applied during the acquisition. ${ }^{13} \mathrm{C}$ chemical shifts were referenced externally to tetramethylsilane using adamantane as a secondary reference. Nitrogen sorption at $77 \mathrm{~K}$ was measured in a Micromeritics 3Flex instrument. Prior to the measurement, the samples were evacuated at $423 \mathrm{~K}$ for $6-7 \mathrm{~h}$ until a residual pressure of $10^{-8}$ bar was reached. The surface area was determined via the BET method, and the $t$-plot method was used to discriminate between the micro- and mesopores. The nonlocal density functional theory model was used to calculate the pore size distributions, assuming slit-shaped pores. ${ }^{41,42}$ Elemental analysis was accomplished as combustion analysis using a Vario microdevice. Optical absorbance spectra of powders were measured on a Shimadzu UV 2600 equipped with an integrating sphere. The emission spectra were recorded on LS-50B PerkinElmer instrument. The excitation wavelength was $350 \mathrm{~nm}$. Time-resolved photoluminescence measurements were carried out at room temperature using the Edinburgh Instruments (FLSP 920) system, equipped with a $450 \mathrm{~W}$ xenon lamp as the excitation source. Scanning electron microscopy images were obtained on a LEO 1550-Gemini microscope. The scanning transmission electron microscopy investigations were performed on an aberration-corrected HD-2700CS (Hitachi; cold-field emitter) operated at an acceleration potential of $200 \mathrm{kV}^{43}$ as well as an aberration-corrected Titan cubed microscope operated at $300 \mathrm{kV}$ (FEI; ultrahigh brightness X-FEG electron source) with an illumination angle of $20.6 \mathrm{mrad}$ and probe current of $c a .60 \mathrm{pA}$. The probe correctors (CEOS) incorporated in these microscope columns provide atomic-resolution capability (beam diameter ca. $0.1 \mathrm{~nm}$ ). Images $(1024 \times 1024$ pixels $)$ were recorded with a HAADF detector with frame times of $c a .15 \mathrm{~s}$. These imaging conditions give rise to atomic number $(Z)$ contrast, a highly sensitive method to detect atoms of strongly scattering elements (high $Z$ ) on light supports. STEM combined with EDS was performed on a Talos microscope (FEI; high brightness field emission gun), operated at an acceleration potential of $200 \mathrm{kV}$. Four EDS detectors were attached to this microscope, allowing one to record EDS maps with good signal-to-noise ratio in relatively short time (here $10-20 \mathrm{~min}$ ). XPS was performed on a Multilab 2000 (Thermo) spectrometer equipped with $\mathrm{Al} \mathrm{K} \alpha$ anode $(h \nu=1486.6 \mathrm{eV})$. All spectra were referenced to the $\mathrm{C} 1 \mathrm{~s}$ peak of adventitious carbon at $284.8 \mathrm{eV}$. For quantification purposes, survey spectra at a pass energy of $50 \mathrm{eV}$ and high-resolution spectra at a pass energy of $20 \mathrm{eV}$ were recorded and analyzed by XPS Peak 4.1 software (written by Raymund Kwok). The spectra were decomposed assuming line shapes as sum functions of Gaussian (80\%) and Lorentzian (20\%) functions. Raw areas determined after subtraction of a Shirley background ${ }^{44}$ were corrected according to following sensitivity factors $^{45}$ (C 1s, 0.25; N 1s, 0.42; O 1s, 0.66; Ag 3d, 5.2). Etching $\mathrm{Ar}^{+}$bombardment was performed at $2 \mathrm{kV}$ and $18 \mathrm{~mA}$ of ionic current. $\zeta$-Potential measurements were performed using Zetasizer nano ZS, and the data analysis was conducted by using "Zetasizer" software. 
Mott-Schottky analysis was performed by measuring impedance spectra of the samples in a potential range from 0.30 to $-0.60 \mathrm{~V}$ RHE, $-0.02 \mathrm{~V}$ potential step, and frequencies from $10 \mathrm{kHz}$ to $0.1 \mathrm{~Hz}, 7 \mathrm{mV}$ potential amplitude. The measurements were performed in a standard three-compartment electrochemical cell. Pt coil and mercury sulfate electrodes were utilized as counter and reference electrodes correspondingly. The curves are presented in reversible hydrogen electrode scale RHE $(0.000 \mathrm{~V} \mathrm{RHE}=-0.635 \mathrm{~V} \mathrm{Ag} / \mathrm{AgCl}$ for $\mathrm{pH} 7.0)$. The measurements were performed in $0.1 \mathrm{M}$ phosphate buffer solution with $\mathrm{pH}$ 7.0. The solution was purged by $\mathrm{N}_{2}$ before the measurements to remove oxygen; a constant flow of $\mathrm{N}_{2}$ was kept during the measurements in order to avoid oxygen leaking into the cell. The electrodes were prepared by deposition of a known amount of the powder on a $\mathrm{Au}$ substrate. Au was chosen as a substrate electrode due to its (1) low interfacial capacity comparing to other typical substrates, such as carbon or metal oxides (ITO, FTO), (2) high surface roughness, and (3) positive surface charge helping to improve the adhesion of powder samples, whose surface is negatively charged. In order to prepare the electrode, the known amount of powder was ultrasonically dispersed in ethanol in order to make 100 $\mathrm{mg} / \mathrm{mL}$ ink. Then $100 \mu \mathrm{L}$ of ink was deposited on the Au substrate in five steps with drying in air between the steps. Finally, $40 \mu \mathrm{L}$ of $5 \%$ solution of Nafion in ethanol was pipetted on the deposit to avoid its detachment. Preliminary experiments with pure Au substrate and $\mathrm{Au}+$ Nafion electrode were performed to demonstrate their negligible contribution into the measured capacity of electrodes with deposited sample powder.

Measured impedance spectra were fitted with the simplest equivalent circuit capable of fitting experimental data: $R_{1}\left(C R_{2}\right)$. Here $R_{1}$ is related to the resistance of the electrolyte, $R_{2}$ is charge transfer resistance due to reduction of residual oxygen and/or evolution of hydrogen (close and below 0,00 V RHE), C is an interfacial capacity predominantly determined by space charge layer in the semiconducting electrode. ${ }^{46}$ In order to take into account frequency dispersion of $C$ due to surface inhomogeneity, the capacity was modeled as constant phase element $Q\left(-Z^{\prime \prime}=1 / C(j \omega)^{\alpha}\right)$ with fixed phase shift constant $\alpha=0.90$.

Hydrogenation of 1-Hexyne. The hydrogenation of 1-hexyne (Acros Organics, 98\%) was carried out in a continuous-flow floodedbed microreactor (ThalesNano H-Cube Pro), in which the liquid alkyne and the gaseous hydrogen (produced in situ by Millipore water electrolysis) flow concurrently upward through a fixed catalytic bed, contained in a cartridge of approximately $3.5 \mathrm{~mm}$ in diameter, and composed of $0.2 \mathrm{~g}$ of catalyst. The liquid feed contained $5 \mathrm{vol} \%$ of substrate and toluene (Fischer Chemicals, 99.95\%) as solvent. The reactions were conducted at various conditions of temperature (303$363 \mathrm{~K})$ and total pressure $(1-20 \mathrm{bar})$ and at constant liquid (1 $\left.\mathrm{cm}^{3} \mathrm{~min}^{-1}\right)$ and $\mathrm{H}_{2}\left(36 \mathrm{~cm}^{3} \mathrm{~min}^{-1}\right)$ flow rates. The reaction products were collected by employing an autosampler, after reaching in $15 \mathrm{~min}$ steady-state operation, and analyzed offline using a gas chromatograph (HP-6890) equipped with a HP-5 capillary column and a flame ionization detector. The reaction rate was expressed as the number of moles of product per mole of metal and unit time. The selectivity to 1hexene, $S$ (1-hexene), was quantified as the amount of the 1-hexene produced divided by the amount of reacted alkyne.

\section{ASSOCIATED CONTENT}

\section{S Supporting Information}

The Supporting Information is available free of charge on the ACS Publications website at DOI: 10.1021/acsnano.5b04210.

Elemental composition of the reference mesoporous graphitic carbon nitride (ref mpg-CN) and AgTCMdoped mpg-CN products; Ag 3d and O 1s XPS spectra as well as the relative content of different $\mathrm{C}, \mathrm{N}$, and $\mathrm{O}$ contributions in the selected samples; $\zeta$-potentials at different $\mathrm{pH}$ values and estimated values of isoelectric points of the reference mpg-CN and AgTCM-doped products; time-resolved photoluminescence spectra of the ref mpg-CN and 3.5\% AgTCM-mpg-CN; MottSchottky plots and band positions of the ref mpg-CN and the selected AgTCM-doped products; time course of $\mathrm{H}_{2}$ evolution reactions using ref mpg-CN and AgTCMdoped solids with and without $\mathrm{Pt}$ assistance; composition and textural properties of catalysts used for hydrogenation studies (PDF)

\section{AUTHOR INFORMATION}

\section{Corresponding Author}

*E-mail: dariya.dontsova@mpikg.mpg.de.

\section{Present Address}

II Institute of Nano Science and Technology (INST), Habitat Centre, Phase-10, Sector-64, Mohali, 160062 Punjab, India.

\section{Notes}

The authors declare no competing financial interest.

\section{ACKNOWLEDGMENTS}

Prof. Hua Gui Yang is acknowledged for PL lifetime measurements. The Scientific Center for Optical and Electron Microscopy (ScopeM) at ETH Zurich is acknowledged for providing access to the facilities.

\section{REFERENCES}

(1) Martin, D. J.; Reardon, P. J. T.; Moniz, S. J. A.; Tang, J. Visible Light-Driven Pure Water Splitting by a Nature-Inspired Organic Semiconductor-Based System. J. Am. Chem. Soc. 2014, 136, 1256812571.

(2) Maeda, K.; Wang, X.; Nishihara, Y.; Lu, D.; Antonietti, M.; Domen, K. Photocatalytic Activities of Graphitic Carbon Nitride Powder for Water Reduction and Oxidation under Visible Light. J. Phys. Chem. C 2009, 113, 4940-4947.

(3) Wang, X.; Maeda, K.; Thomas, A.; Takanabe, K.; Xin, G.; Carlsson, J. M.; Domen, K.; Antonietti, M. A Metal-Free Polymeric Photocatalyst for Hydrogen Production from Water under Visible Light. Nat. Mater. 2009, 8, 76-80.

(4) Thomas, A.; Fischer, A.; Goettmann, F.; Antonietti, M.; Muller, J.-O.; Schlogl, R.; Carlsson, J. M. Graphitic Carbon Nitride Materials: Variation of Structure and Morphology and Their Use as Metal-Free Catalysts. J. Mater. Chem. 2008, 18, 4893-4908.

(5) Wang, X.; Chen, X.; Thomas, A.; Fu, X.; Antonietti, M. MetalContaining Carbon Nitride Compounds: A New Functional OrganicMetal Hybrid Material. Adv. Mater. 2009, 21, 1609-1612.

(6) Li, X.; Guo, Z.; Li, J.; Zhang, Y.; Ma, H.; Pang, X.; Du, B.; Wei, Q. Quenched Electrochemiluminescence of Ag Nanoparticles Functionalized g- $\mathrm{C}_{3} \mathrm{~N}_{4}$ by Ferrocene for Highly Sensitive Immunosensing. Anal. Chim. Acta 2015, 854, 40-46.

(7) Xu, L.; Li, H.; Xia, J.; Wang, L.; Xu, H.; Ji, H.; Li, H.; Sun, K. Graphitic Carbon Nitride Nanosheet Supported High Loading Silver Nanoparticle Catalysts for the Oxygen Reduction Reaction. Mater. Lett. 2014, 128, 349-353.

(8) Bai, X.; Zong, R.; Li, C.; Liu, D.; Liu, Y.; Zhu, Y. Enhancement of Visible Photocatalytic Activity via $\mathrm{Ag} @ \mathrm{C}_{3} \mathrm{~N}_{4}$ Core-Shell Plasmonic Composite. Appl. Catal., B 2014, 147, 82-91.

(9) Jiang, D.; Zhang, Y.; Chu, H.; Liu, J.; Wan, J.; Chen, M. N-doped Graphene Quantum Dots as an Effective Photocatalyst for the Photochemical Synthesis of Silver Deposited Porous Graphitic $\mathrm{C}_{3} \mathrm{~N}_{4}$ Nanocomposites for Nonenzymatic Electrochemical $\mathrm{H}_{2} \mathrm{O}_{2}$ Sensing. RSC Adv. 2014, 4, 16163-16171.

(10) $\mathrm{Bu}$, Y.; Chen, Z.; Li, W. Using Electrochemical Methods to Study the Promotion Mechanism of the Photoelectric Conversion Performance of Ag-Modified Mesoporous g- $\mathrm{C}_{3} \mathrm{~N}_{4}$ Heterojunction Material. Appl. Catal., B 2014, 144, 622-630.

(11) Peng, H.; Mo, Z.; Liao, S.; Liang, H.; Yang, L.; Luo, F.; Song, H.; Zhong, Y.; Zhang, B. High Performance Fe- and N- Doped Carbon 
Catalyst with Graphene Structure for Oxygen Reduction. Sci. Rep. 2013, 3, 1765 .

(12) Ge, L.; Han, C.; Liu, J.; Li, Y. Enhanced Visible Light Photocatalytic Activity of Novel Polymeric g- $\mathrm{C}_{3} \mathrm{~N}_{4}$ Loaded with $\mathrm{Ag}$ Nanoparticles. Appl. Catal., A 2011, 409-410, 215-222.

(13) Katsumata, H.; Sakai, T.; Suzuki, T.; Kaneco, S. Highly Efficient Photocatalytic Activity of $\mathrm{g}^{-} \mathrm{C}_{3} \mathrm{~N}_{4} / \mathrm{Ag}_{3} \mathrm{PO}_{4}$ Hybrid Photocatalysts through Z-Scheme Photocatalytic Mechanism under Visible Light. Ind. Eng. Chem. Res. 2014, 53, 8018-8025.

(14) Jiang, D.; Zhu, J.; Chen, M.; Xie, J. Highly Efficient Heterojunction Photocatalyst Based on Nanoporous g- $\mathrm{C}_{3} \mathrm{~N}_{4}$ Sheets Modified by $\mathrm{Ag}_{3} \mathrm{PO}_{4}$ Nanoparticles: Synthesis and Enhanced Photocatalytic Activity. J. Colloid Interface Sci. 2014, 417, 115-120.

(15) Kumar, S.; Surendar, T.; Baruah, A.; Shanker, V. Synthesis of a Novel and Stable g- $\mathrm{C}_{3} \mathrm{~N}_{4}-\mathrm{Ag}_{3} \mathrm{PO}_{4}$ Hybrid Nanocomposite Photocatalyst and Study of the Photocatalytic Activity under Visible Light Irradiation. J. Mater. Chem. A 2013, 1, 5333-5340.

(16) Yang, X.; Tang, H.; Xu, J.; Antonietti, M.; Shalom, M. Silver Phosphate/Graphitic Carbon Nitride as an Efficient Photocatalytic Tandem System for Oxygen Evolution. ChemSusChem 2015, 8, 13501358

(17) Ren, H.-T.; Jia, S.-Y.; Wu, Y.; Wu, S.-H.; Zhang, T.-H.; Han, X. Improved Photochemical Reactivities of $\mathrm{Ag}_{2} \mathrm{O} / \mathrm{g}-\mathrm{C}_{3} \mathrm{~N}_{4}$ in Phenol Degradation under UV and Visible Light. Ind. Eng. Chem. Res. 2014, 53, 17645-17653.

(18) Jiang, D.; Chen, L.; Xie, J.; Chen, M. $\mathrm{Ag}_{2} \mathrm{~S} / \mathrm{g}-\mathrm{C}_{3} \mathrm{~N}_{4}$ Composite Photocatalysts for Efficient Pt-free Hydrogen Production. The cocatalyst Function of $\mathrm{Ag} / \mathrm{Ag}_{2} \mathrm{~S}$ Formed by Simultaneous Photodeposition. Dalton Trans. 2014, 43, 4878-4885.

(19) Bu, Y.; Chen, Z.; Feng, C.; Li, W. Study of the Promotion Mechanism of the Photocatalytic Performance and Stability of the $\mathrm{Ag} @ \mathrm{AgCl} / \mathrm{g}-\mathrm{C}_{3} \mathrm{~N}_{4}$ Composite under Visible Light. RSC Adv. 2014, 4, 38124-38132.

(20) Cao, J.; Zhao, Y.; Lin, H.; Xu, B.; Chen, S. Ag/AgBr/g-C $\mathrm{C}_{3}$ : A Highly Efficient and Stable Composite Photocatalyst for Degradation of Organic Contaminants under Visible Light. Mater. Res. Bull. 2013, 48, 3873-3880.

(21) Xu, Y.-S.; Zhang, W.-D. Ag/AgBr-Grafted Graphite-like Carbon Nitride with Enhanced Plasmonic Photocatalytic Activity under Visible Light. ChemCatChem 2013, 5, 2343-2351.

(22) Wang, Y.; Yao, J.; Li, H.; Su, D.; Antonietti, M. Highly Selective Hydrogenation of Phenol and Derivatives over a Pd@Carbon Nitride Catalyst in Aqueous Media. J. Am. Chem. Soc. 2011, 133, 2362-2365.

(23) Li, Y.; Xu, X.; Zhang, P.; Gong, Y.; Li, H.; Wang, Y. Highly Selective Pd@mpg- $\mathrm{C}_{3} \mathrm{~N}_{4}$ Catalyst for phenol Hydrogenation in Aqueous Phase. RSC Adv. 2013, 3, 10973-10982.

(24) Li, Y.; Gong, Y.; Xu, X.; Zhang, P.; Li, H.; Wang, Y. A Practical and Benign Synthesis of Amines Through Pd@mpg- $\mathrm{C}_{3} \mathrm{~N}_{4}$ Catalyzed Reduction of Nitriles. Catal. Commun. 2012, 28, 9-12.

(25) Gong, Y.; Zhang, P.; Xu, X.; Li, Y.; Li, H.; Wang, Y. A Novel Catalyst Pd@ompg- $\mathrm{C}_{3} \mathrm{~N}_{4}$ for Highly Chemoselective Hydrogenation of Quinoline under Mild Conditions. J. Catal. 2013, 297, 272-280.

(26) Deng, D.; Yang, Y.; Gong, Y.; Li, Y.; Xu, X.; Wang, Y. Palladium Nanoparticles Supported on mpg- $\mathrm{C}_{3} \mathrm{~N}_{4}$ as active Catalyst for Semihydrogenation of Phenylacetylene under Mild Conditions. Green Chem. 2013, 15, 2525-2531.

(27) Anderson, J. A.; Mellor, J.; Wells, R. P. K. Pd Catalysed Hexyne Hydrogenation Modified by Bi and by Pb. J. Catal. 2009, 261, 208216.

(28) Vilé, G.; Pérez-Ramírez, J. Beyond the Use of Modifiers in Selective Alkyne Hydrogenation: Silver and Gold Nanocatalysts in Flow Mode for Sustainable Alkene Production. Nanoscale 2014, 6, 13476-13482.

(29) Wang, X.; Maeda, K.; Chen, X.; Takanabe, K.; Domen, K.; Hou, Y.; Fu, X.; Antonietti, M. J. Am. Chem. Soc. 2009, 131, 1680-1681.

(30) Lotsch, B. V. From Molecular Building Blocks to Condensed Carbon Nitride Networks: Structure and Reactivity. PhD Dissertation, LMU Munich, 2006.
(31) Zheng, Y.; Jiao, Y.; Zhu, Y.; Li, L. H.; Han, Y.; Chen, Y.; Du, A.; Jaroniec, M.; Qiao, S. Z. Hydrogen Evolution by a Metal-Free Electrocatalyst. Nat. Commun. 2014, 5, 3783.

(32) Panasiuk, Y. V.; Raevskaya, A. E.; Stroyuk, O. L.; Lytvyn, P. M.; Kuchmiy, S. Y. Preparation and Optical Properties of Highly Luminescent Colloidal Single-Layer Carbon Nitride. RSC Adv. 2015, $5,46843-46849$

(33) Chen, Z. P.; Antonietti, M.; Dontsova, D. Enhancement of the Photocatalytic Activity of Carbon Nitrides by Complex Templating. Chem. - Eur. J. 2015, 21, 10805-10811.

(34) Shalom, M.; Inal, S.; Fettkenhauer, C.; Neher, D.; Antonietti, M. Improving Carbon Nitride Photocatalysis by Supramolecular Preorganization of Monomers. J. Am. Chem. Soc. 2013, 135, 7118-7121.

(35) Vilé, G.; Almora-Barrios, N.; Mitchell, S.; López, N.; PérezRamírez, J. From the Lindlar Catalyst to Supported Ligand-Modified Palladium Nanoparticles: Selectivity Patterns and Accessibility Constraints in the Continuous-Flow Three-Phase Hydrogenation of Acetylenic Compounds. Chem. - Eur. J. 2014, 20, 5926-5937.

(36) Vilé, G.; Baudouin, D.; Remediakis, I. N.; Copéret, C.; López, N.; Pérez-Ramírez, J. Silver Nanoparticles for Olefin Production: New Insights into the Mechanistic Description of Propyne Hydrogenation. ChemCatChem 2013, 5, 3750-3759.

(37) Vilé, G.; Albani, D.; Nachtegaal, M.; Chen, Z.; Dontsova, D.; Antonietti, M.; López, N.; Pérez-Ramírez, J. A stable single-site palladium catalyst for hydrogenations. Angew. Chem., Int. Ed. 2015, 54, $11265-11269$.

(38) Vilé, G.; Wrabetz, S.; Floryan, L.; Schuster, M. E.; Girgsdies, F.; Teschner, D.; Pérez-Ramírez, J. Stereo and Chemoselective Character of Supported $\mathrm{CeO}_{2}$ Catalysts for Continuous-Flow Three-Phase Alkyne Hydrogenation. ChemCatChem 2014, 6, 1928-1934.

(39) Øygarden, A. H.; Pérez-Ramírez, J.; Waller, D.; Schöffel, K.; Brackenbury, D. Patent Appl. WO2004/110622, 2004.

(40) Schwarze, M.; Stellmach, D.; Schroder, M.; Kailasam, K.; Reske, R.; Thomas, A.; Schomacker, R. Quantification of Photocatalytic Hydrogen Evolution. Phys. Chem. Chem. Phys. 2013, 15, 3466-3472.

(41) Tarazona, P. Free-Energy Density Functional for Hard Spheres. Phys. Rev. A: At., Mol., Opt. Phys. 1985, 31, 2672-2679.

(42) Tarazona, P.; Marini Bettolo Marconi, U.; Evans, R. Phase Equilibria of Fluid Interfaces and Confined Fluids. Mol. Phys. 1987, 60, $573-595$.

(43) Krumeich, F.; Mueller, E.; Wepf, R. A.; Nesper, R. Characterization of Catalysts in an Aberration-Corrected Scanning Transmission Electron Microscope. J. Phys. Chem. C 2011, 115, 1080-1083.

(44) Shirley, D. A. High-Resolution X-Ray Photoemission Spectrum of the Valence Bands of Gold. Phys. Rev. B 1972, 5, 4709-4714.

(45) Wagner, C. D.; Davis, L. E.; Zeller, M. V.; Taylor, J. A.; Raymond, R. H.; Gale, L. H. Empirical Atomic Sensitivity Factors for Quantitative Analysis by Electron Spectroscopy for Chemical Analysis. Surf. Interface Anal. 1981, 3, 211-225.

(46) Krishnan, R. Fundamentals of Semiconductor Electrochemistry and Photoelectrochemistry. In Encyclopedia of Electrochemistry; Bard, A. J., Stratmann, M., Licht, S., Eds.; Wiley-VCH: Weinheim, Germany, 2007; pp 1-53. 